\title{
Subunit Components in Salt-soluble and Insoluble Fractions of Carp Myofibrils during Frozen Storage
}

\author{
Kuniaki Yoshikawa, ${ }^{* 1}$ Norio Inoue, ${ }^{* 2}$ Yuji Kawai, ${ }^{* 2}$ and Haruo Shinano ${ }^{* 2}$ \\ ${ }^{* 1}$ Central Research Laboratory, Taiyo Kagaku Co., Ltd., Takaramachi, Yokkaichi, Mie 510, Japan \\ ${ }^{* 2}$ Faculty of Fisheries, Hokkaido University, Minato, Hakodate, Hokkaido 041, Japan
}

(Received November 2, 1994)

\begin{abstract}
The changes of subunit components in salt $(0.6 \mathrm{M} \mathrm{KCl})$-soluble and salt-insoluble fractions of carp myofibrils during frozen storage were followed by $7.5 \%$ polyacrylamide gel electrophoresis. Myofibrillar samples were suspended in $0.1 \mathrm{M} \mathrm{KCl}$ solution containing 5 and $20 \mathrm{~mm}$ Tris-maleate buffer $(\mathrm{pH} 7.2)$, and in $0.1 \mathrm{M} \mathrm{KCl}$ solution without a buffer. Prepared samples were stored at three different temperatures: $-4,-11$, and $-26^{\circ} \mathrm{C}$. When the solubility decreased after $2-3$ weeks at -4 and $-11^{\circ} \mathrm{C}$, the main components of the myofibrils in the salt-soluble fraction decreased and were detectable in the saltinsoluble fraction. The decrease of salt-soluble protein at $-11^{\circ} \mathrm{C}$ was larger than that observed at $-4^{\circ} \mathrm{C}$. At $-4^{\circ} \mathrm{C}$ storage, the extent of the decrease in the salt-soluble fraction and consequently that of the increase in the salt-insoluble fraction was relatively larger in the actin (A) component than in the myosin heavy chain $(\mathrm{HC})$ component. At $-11^{\circ} \mathrm{C}$ storage, the shift of $\mathrm{HC}$ component from the salt-soluble fraction to the salt-insoluble fraction on the last day of storage was larger than that of the A component in three Tris concentrations. As for the salt-insoluble fraction, the aggregated proteins which could not migrate into $7.5 \%$ polyacrylamide gel ( $>\mathrm{G}$ component) was found to be larger in the model system without the buffer than in that containing the buffer at any storage temperature. It seems that the formation of the $>\mathrm{G}$ component at -11 and $-26^{\circ} \mathrm{C}$ without buffer accompanied the $\mathrm{HC}$ component.
\end{abstract}

Key words: carp, myofibril, frozen storage, freeze denaturation

In a previous paper, ") we reported that the changes in solubility and ATPase activity of carp myofibrils during frozen storage could be explained in terms of the amount and concentration of unfrozen salt solution. ATPase inactivation is assumed to be caused by a small amount of highly concentrated unfrozen $\mathrm{KCl}$ solution when myofibrils are stored above the $\mathrm{KCl}$ eutectic point. The myofibrils are also thought to be affected, as they move closer together and become insoluble when the quantity of unfrozen solution is lesser at the same storage temperature. In the latter case, the decrease in soluble protein was larger than the decrease in ATPase activity, and subsequently the allocated activity ${ }^{1)}$ was detected in a precipitate (salt-insoluble) fraction.

It has been reported that the ATPase activity of myosin $B$ decreases while remaining highly soluble. ${ }^{2,3)}$ It has been revealed that carp F-actin is denatured as a result of exposure to concentrated $\mathrm{KCl}$ solution and the $\mathrm{F}$-actin structure changes from its filamentous state to small-sized filaments or aggregates. ${ }^{4,5}$ Ohnishi and Roger ${ }^{6}$ reported the relationship between actomyosin filament shortening and loss of protein solubility during frozen storage using gel-filtration, sodium dodecylsulfate polyacrylamide gel electrophoresis (SDS-PAGE), and electron microscopic observation to compare salt $(0.5 \% \mathrm{NaCl})$ soluble proteins prepared from both fresh and frozen cod muscle. Umemoto showed that insoluble aggregation (gel fraction) in a salt solution ( $0.45 \mathrm{M} \mathrm{KCl}$-phosphate buffer) was observed during frozen storage of flatfish and cod muscle. ${ }^{7} \mathrm{He}$ also detected myosin and actin components in this gel fraction by measuring its biochemical properties. In these experi- ments, subunit components have not yet been quantitatively determined in the salt-soluble and gel fractions.

This paper describes the differences in subunit component content in the supernatant (salt-soluble) and precipitate (salt-insoluble) fractions prepared in the previous paper ${ }^{1)}$ by using SDS-PAGE, and identifies the main components related to the aggregation of protein molecules during frozen storage.

\section{Materials and Methods}

\section{Materials}

Dorsal laternal muscles of live carp Cyprinus carpio (weight, $c a .1 \mathrm{~kg}$; length, $c a .30 \mathrm{~cm}$ ) were used for this experiment.

\section{Preparation of Myofibrils}

Myofibrils were prepared by the same method described in the previous paper. ${ }^{1)}$ The myofibrils were finally suspended in the following three solutions: $0.1 \mathrm{M} \mathrm{KCl}$ solution without buffer, and $0.1 \mathrm{M} \mathrm{KCl}$ solution containing either 5 or $20 \mathrm{~mm}$ Tris-maleate buffer (pH 7.2). The solutions were labelled 0,5 , and $20 \mathrm{~mm}$ Tris, respectively.

\section{Conditions of Freezing, Storage, and Thawing}

The procedure was the same as described previously. ${ }^{1)}$

\section{Solubility, Soluble Protein, and Protein Concentration}

Determinations of solubility, soluble protein, and protein concentration were the same as described in the previous paper." The supernatant and precipitate frac- 


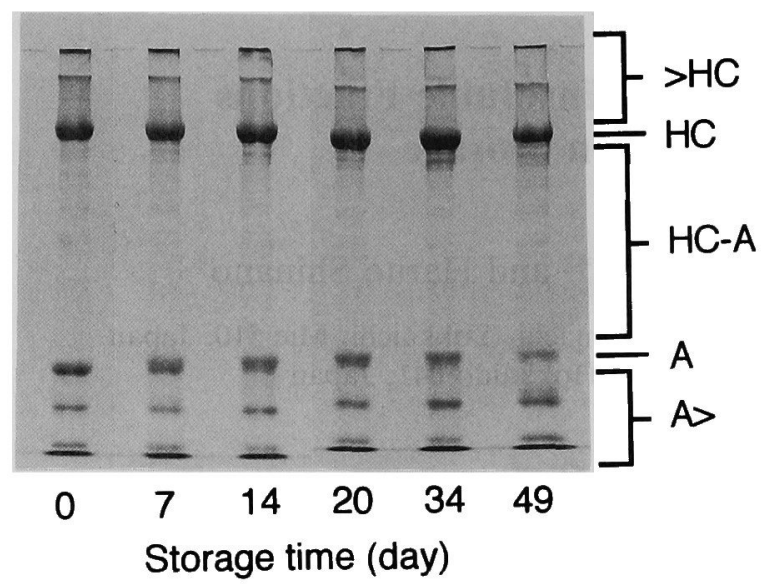

Fig. 1. Changes in SDS-polyacrylamide gel electrophoretic pattern of salt-soluble fraction during frozen storage at $-4^{\circ} \mathrm{C}$.

The abbreviations used are as described under "Materials and Methods".

tions, after centrifugation, were labelled as the salt-soluble fraction (soluble fraction) and salt-insoluble fraction (insoluble fraction), respectively.

\section{SDS-PAGE Analysis}

Samples for SDS-PAGE were prepared using a similar procedure as described by Numakura et al. ${ }^{8)}$ Parts of the total fraction and soluble fraction were dissolved in $2 \%$ SDS-2\% 2-mercaptoethanol-8 M urea-20 mM Tris. $\mathrm{HCl}$ (pH 8.0) and then heated for $1 \mathrm{~min}$ in a boiling water bath. Electrophoresis on $7.5 \%$ gels was similar to that described by Laemmli, ${ }^{9)}$ and coomassie brilliant blue R250 was used for the staining of gels.

Figure 1 shows the SDS-PAGE patterns for the soluble fraction of $20 \mathrm{mM}$ Tris at $-4^{\circ} \mathrm{C}(0-7$ weeks storage). These patterns show that the actin component decreases with increasing storage period. In this study, the amount of the main components and the pooled components, such as myosin heavy chain (HC), actin (A), and other components migrating between $\mathrm{HC}$ and $\mathrm{A}$ (HC-A), faster than $\mathrm{A}$ $(\mathrm{A}>$ ), and slower than $\mathrm{HC}(>\mathrm{HC})$ were quantitatively estimated by densitometry and expressed as a relative intensity (\%). A Shimazu CS-9000 was used for densitometric scans of electrophoretic gels. The amount of proteins which were too large to migrate into the gel was calculated from the balance of the amount of protein used for the gel and the amount of protein estimated by the staining intensity of the gel, and expressed as a > G component. The percentage of insoluble fraction was calculated from the balance of the total fraction and soluble fraction. Furthermore, the percentages of each component in both soluble and insoluble fractions were calculated as a part of the total fraction.

\section{Results}

In the samples of $0 \mathrm{~mm}$ Tris at $-4^{\circ} \mathrm{C}, \mathrm{HC}, \mathrm{A}$, and $\mathrm{A}>$ components were both decreased in the soluble fraction and increased in the insoluble fraction after 20 days of storage (Fig. 2A). Furthermore, > HC components showed a similar and pronounced shift. The decreases of $\mathrm{HC}$ and A components in the soluble fraction in the later storage stage (34-49 days) were 50.0-70.7 and 74.8-84.4\% of their original amounts, respectively. This means that the A component was present in relatively large amounts in the insoluble fraction.

In $0 \mathrm{mM}$ Tris at $-11^{\circ} \mathrm{C}$ (Fig. 2B), the shift patterns for each component were quite similar to that stored at $-4^{\circ} \mathrm{C}$ (Fig. 2A). The shift occurred markedly after 20 days of
(A) $-4^{\circ} \mathrm{C}$

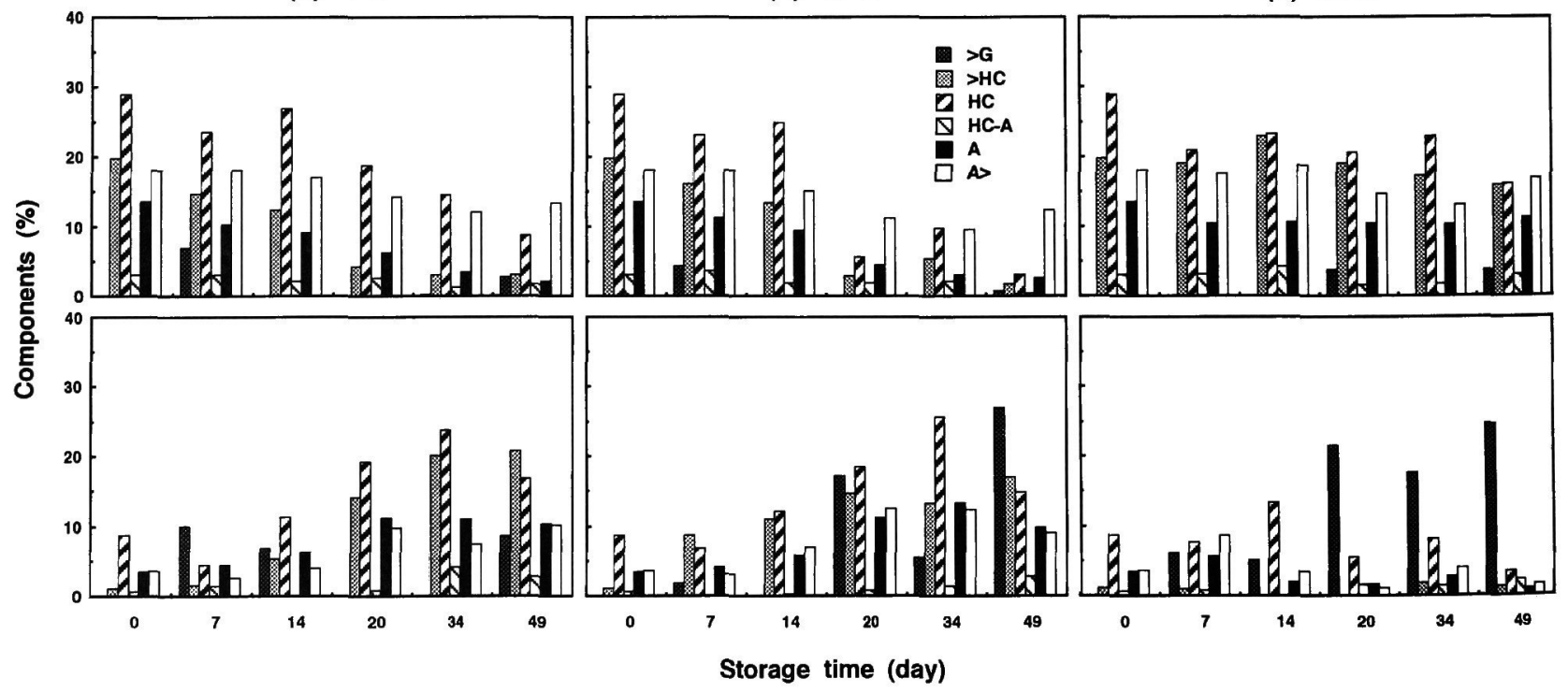

Fig. 2. Changes in subunit components of salt-soluble and insoluble fractions during frozen storage at various temperatures in a $0.1 \mathrm{M} \mathrm{KCl}$ solution without buffer (0 mM Tris).

Upper panels, salt-soluble fraction; lower panels, salt-insoluble fraction.

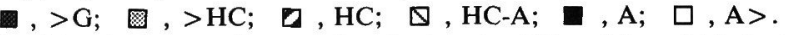

The abbreviations used are as described under "Materials and Methods". 
storage, and the degree of shift was the largest among the three different storage temperatures examined in this study. The decreases of $\mathrm{HC}$ and A components in the soluble fraction in 20-49 storage days were 66.9-90.3 and $67.4-82.2 \%$ of their original amounts, respectively. The decrease of total $\mathrm{HC}$ component (the sum in the soluble and insoluble fractions) after 20 and 49 days were 36.2 and $53.2 \%$ of its original total amount, respectively. At the time, $>\mathrm{G}$ components increased in the insoluble fraction (Fig. 2B).

In the $0 \mathrm{~mm}$ Tris at $-26^{\circ} \mathrm{C}$, the $\mathrm{HC}$ component in the soluble fraction remained almost constant from the 7th to 34th day of storage (Fig. 2C). A large amount of A component was present in the soluble fraction throughout storage. The decreases (average values) of $\mathrm{HC}$ and A components (the sum in the soluble and insoluble fractions) in $20-49$ days of storage were 32.5 and $27.4 \%$, respectively, while the $>\mathrm{G}$ component increased in the insoluble fraction.

In the case of $5 \mathrm{~mm}$ Tris, the shifts and changes of each component showed a similar tendency to those of $0 \mathrm{mM}$ Tris, although to a lesser degree (Fig. 3A-C). At $-26^{\circ} \mathrm{C}$
(A) $-4^{\circ} \mathrm{C}$

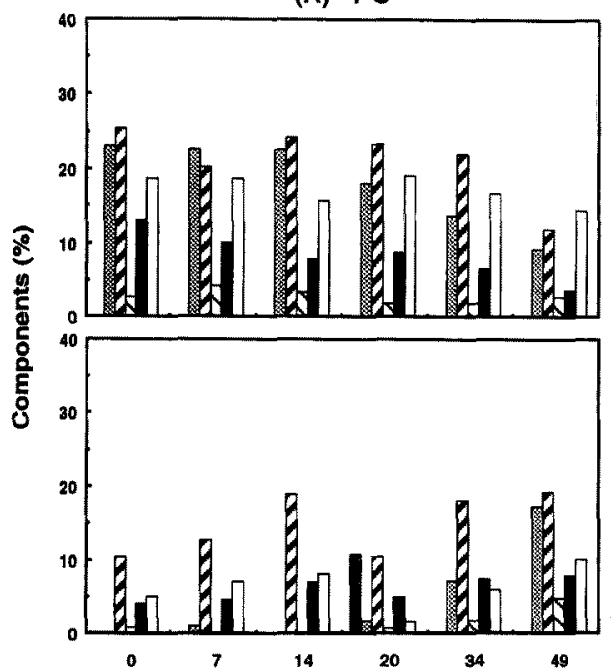

(B) $-11^{\circ} \mathrm{C}$

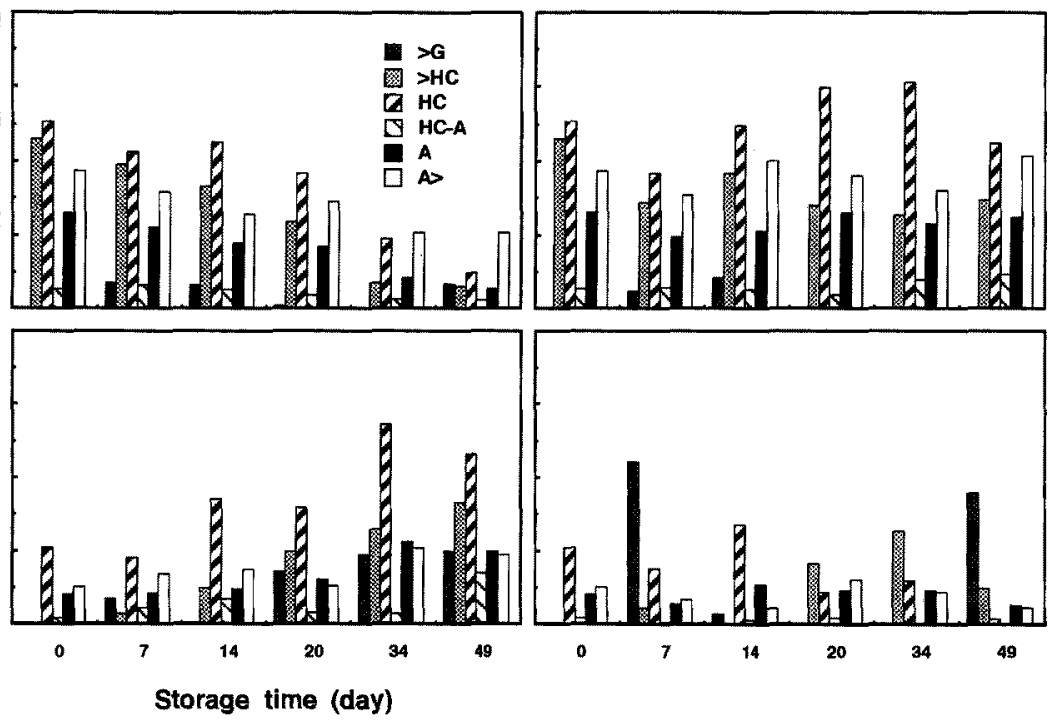

Fig. 3. Changes in subunit components of salt-soluble and insoluble fractions during frozen storage at various temperatures in a $0.1 \mathrm{M} \mathrm{KCl}$ solution containing $5 \mathrm{~mm}$ Tris-maleate buffer ( $5 \mathrm{~mm}$ Tris).

Panels and symbols are as in Fig. 2.

(A) $-4^{\circ} \mathrm{C}$

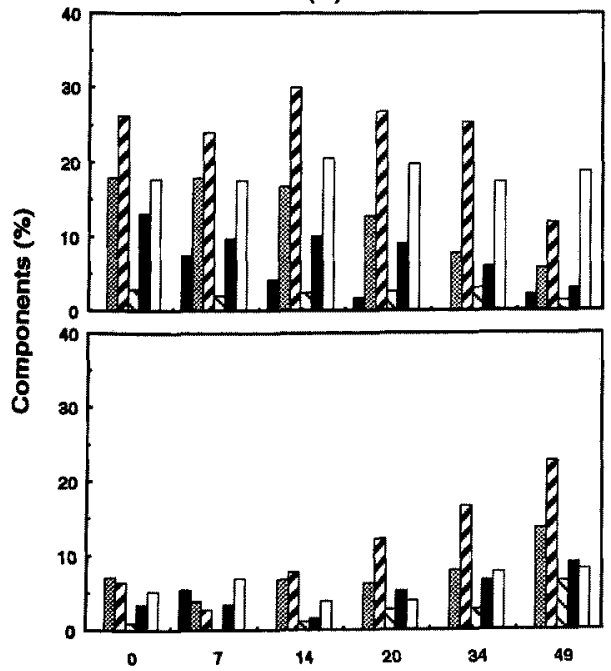

(B) $-11^{\circ} \mathrm{C}$
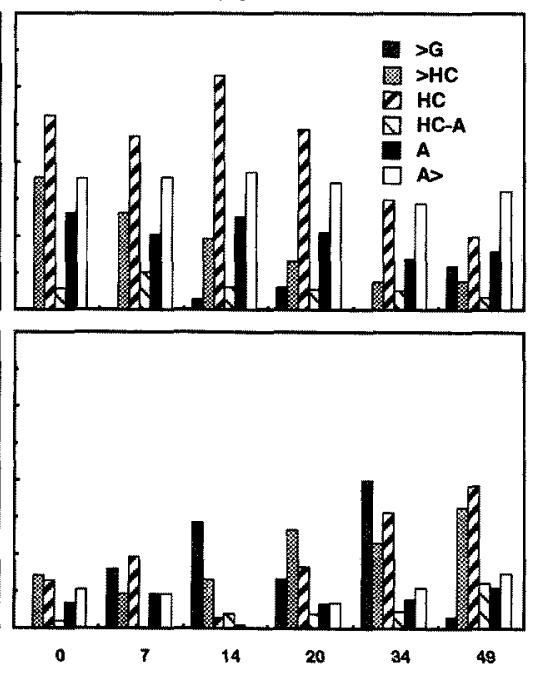

Storage time (day)
(C) $-26^{\circ} \mathrm{C}$

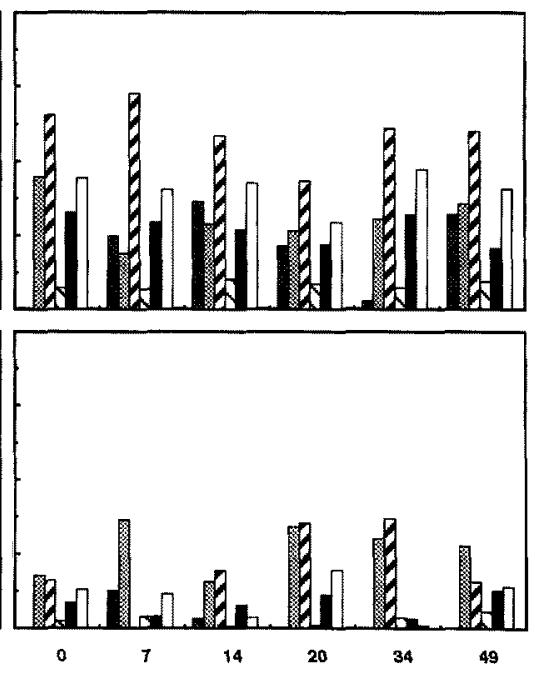

Fig. 4. Changes in subunit components of salt-soluble and insoluble fractions during frozen storage at various temperatures in a $0.1 \mathrm{M} \mathrm{KCl}$ solution containing $20 \mathrm{mM}$ Tris-maleate buffer (20 mM Tris).

Panels and symbols are as in Fig. 2. 
storage (Fig. 3C), the decrease of total HC component (the sum in the soluble and insoluble fractions) at both the 7 th and 49 th day of storage were 27.6 and $35.5 \%$ of its original amount, respectively, and the $>G$ component increased in the insoluble fraction as a counterpart to the above decrement.

As for $20 \mathrm{~mm}$ Tris, the shifts and changes in each component were smaller than those seen in the case of $5 \mathrm{~mm}$ Tris. At $-4^{\circ} \mathrm{C}$ storage (Fig. $4 \mathrm{~A}$ ), the amount of $\mathrm{HC}$ and $\mathrm{A}$ component in the soluble fraction noticeably decreased after 49 days. In particular, the $>\mathrm{G}$ component was present in the soluble fraction when stored at $-26^{\circ} \mathrm{C}$ (Fig. $4 \mathrm{C}$ ).

\section{Discussion}

The subunit components in the salt-soluble fraction at $-26^{\circ} \mathrm{C}$, which is below the $\mathrm{KCl}$ eutectic point, showed the smallest changes among the three storage temperatures examined in all Tris concentrations including $0 \mathrm{mM}$ Tris. This correlates with results from the previous report ${ }^{1)}$ which showed that the decrease in soluble protein and ATPase activity was the smallest.

In the previous paper, ${ }^{1}$ we reported that the decrease of soluble protein was larger under the conditions of lower Tris concentration at $-11^{\circ} \mathrm{C}$ storage, which is near the $\mathrm{KCl}$ eutectic point. With an accompanying decrease of soluble protein in the soluble fraction, each component in the fraction shifted to the insoluble fraction in the three Tris systems examined (Figs. 2B, 3B, and 4B). When samples were stored above the $\mathrm{KCl}$ eutectic point at $-4^{\circ} \mathrm{C}$, a similar shift occurred, but to a lesser degree than that observed at $-11^{\circ} \mathrm{C}$.

The presence of $\mathrm{HC}$ and $\mathrm{A}$ components was compared in soluble and insoluble fractions when the aggregation and inactivation of myofibrillar ATPase was observed during storage above the $\mathrm{KCl}$ eutectic point at $-4^{\circ} \mathrm{C}$. The $\mathrm{A}$ component in the three cases of Tris concentrations decreased more than the $\mathrm{HC}$ component in the soluble fraction during the storage period. This suggests that a relatively large amount of $\mathrm{A}$ component was shifted from the soluble fraction to the insoluble fraction. At $-11^{\circ} \mathrm{C}$ storage, the shift of $\mathrm{HC}$ component from the soluble fraction to the insoluble fraction by the last day of storage was larger than that of the A component in the three Tris concentrations.

Comparing the three Tris concentration samples, the amount of $>\mathrm{G}$ component was largest in $0 \mathrm{mM}$ Tris (Figs. 2-4). The percentage loss for the total amount of $\mathrm{HC}$ component (the sum in the soluble and insoluble fractions) was calculated from the differences between both of them on the initial and last day (49th day) of storage. Their values at $-4,-11$, and $-26^{\circ} \mathrm{C}$ were $33.0,53.2$, and $48.7 \%$, respectively. Also, the percentage loss for the total amount of A component was calculated using a similar procedure, and was $26.6,28.4$, and $29.0 \%$ in the same temperature order, respectively. From these results at -11 and $-26^{\circ} \mathrm{C}$, which had large $>\mathrm{G}$ component amounts, it is assumed that the $\mathrm{HC}$ component was largely related to the formation of the $>\mathrm{G}$ component.

As for the samples of $20 \mathrm{~mm}$ Tris at $-26^{\circ} \mathrm{C}$, when the $>\mathrm{G}$ component was found in the soluble fraction, the total HC components from both the soluble fraction and insoluble fraction did not decrease during storage. This indicated that the $>\mathrm{G}$ component and its degree of aggregation in this case $\left(20 \mathrm{mM}\right.$ Tris at $\left.-26^{\circ} \mathrm{C}\right)$ differed from that observed in the insoluble fraction of $0 \mathrm{~mm}$ Tris samples. Since the $>\mathrm{G}$ component in the case of $0 \mathrm{mM}$ Tris at -11 and $-26^{\circ} \mathrm{C}$, occupied $20-25 \%$ of the total fraction, 40 and $70 \%$ of the aggregated matter could be dissolved under reduced conditions, respectively. These values have been calculated from the balance of protein amount in the insoluble fraction and $>\mathrm{G}$ component. Since the $>\mathrm{G}$ component in all cases was insoluble in the preparative solution for the SDS-PAGE, it is supposed that covalent bonds except disulfide bond ${ }^{10)}$ are related to the formation of $>\mathrm{G}$ components. No clear explanation, however, can be given regarding the irregular appearance of the $>G$ component. As the $>\mathrm{G}$ component appeared irregularly in the insoluble fraction, it is thought that nonspecific entangled aggregation was tightly formed.

\section{References}

1) K. Yoshikawa, N. Inoue, Y. Kawai, and H. Shinano: Changes of the solubility and ATPase activity of carp myofibrils during frozen storage at different temperatures. Fisheries Sci., 61, 804-812 (1995).

2) N. Inoue, M. Oguni, M. Yamamoto, and H. Shinano: Electron microscopic observation and biochemical properties of carp myosin B during frozen storage at $-8^{\circ} \mathrm{C}$ with cryoprotectants. Trans. Japan. Assoc. Refrig., 9, 93-99 (1992) (in Japanese).

3) M. Oguni, N. Inoue, K. Ohi, and H. Shinano: Denaturation of carp myosin $\mathrm{B}$ during frozen and supercooled storage at $-8^{\circ} \mathrm{C}$. Nippon Suisan Gakkaishi, 53, 789-794 (1987) (in Japanese).

4) T. Okada, N. Inoue, and H. Shinano: An explanation of freeze denaturation on the kinetics of thermal inactivation of frozenstored carp myosin B. Nippon Suisan Gakkaishi, 52, 1765-1770 (1986) (in Japanese).

5) T. Okada, N. Inoue, and H. Shinano: Influence of $\mathrm{KCl}$ concentration on the denaturation of carp F-actin. Nippon Suisan Gakkaishi, 54, 2037-2042 (1988) (in Japanese).

6) M. Ohnishi and G.W. Rodger: Analysis of the salt-soluble protein fraction of cod muscle by gel filtration, in "Advances in Fish Science and Technology"' (ed. by J. J. Connell), Fishing News Books Ltd., Farnham, 1980, pp. 422-428.

7) S. Umemoto: Studies on gel fraction of fish muscle protein extractsII. Some properties of gel fraction protein. Nippon Suisan Gakkaishi, 37, 1182-1186 (1971) (in Japanese).

8) T. Numakura, N. Seki, I. Kimura, K. Toyoda, T. Fujita, K. Takama, and K. Arai: Cross-linking reaction of myosin in the fish paste during setting (SUWARI). Nippon Suisan Gakkaishi, 51, 1559-1565 (1985) (in Japanese).

9) U. K. Laemmli: Cleavage of structural proteins during the assembly of the head of bacteriophage T4. Nature, 227, 680-685 (1970).

10) Y. Tsuchiya, T. Tsuchiya, and J. J. Matsumoto: The nature of the cross-bridges constituting aggregates of frozen stored carp myosin and actomyosin, in "Advances in Fish Science and Technology" (ed. by J. J. Connell), Fishing News Books Ltd., Farnham, 1980, pp. 434-438. 